\title{
Escritura y Tradición: El Martín Fierro en Dos Cuentos de Borges
}

Vencen los bárbaros, los gauchos vencen.

"Poema conjetural"

Leer a Borges como otro continuador de la tradición gauchesca bien podría ser un proyecto predestinado a la irrisión. Cualquier clasificación temática de la obra creadora del maestro argentino incide de por sí en una arbitrariedad crítica cuyos límites impiden abarcar el tratamiento a que los motivos literarios han sido sometidos. Pero también sería ingenuo ignorar -cúmplese de alguna manera borgiana nuestro destinoque a lo largo de la obra de Borges se encuentra toda una serie de reflexiones sobre la literatura gauchesca, especialmente sobre la poesía, ya sea como tradición literaria propiamente o como expresión de una estructura mítica argentina, que rebasan sus ensayos críticos para instalarse, con función intrínseca, en sus narraciones y poemas. Si bien su crítica detalla una profunda toma de conciencia de esta tradición literaria nacional, la cual enmarca la totalidad de su obra, sus narraciones y poesía incorporan esta tradición, leyendo y reescribiéndola.

Señalar ciertos elementos de una experiencia gauchesca en la obra de Borges es nuestro propósito. Para ello, nuestra reducida lectura oscilará entre los vasos comunicantes de los textos críticos en que Borges examina la tradición de la poesía gauchesca y de dos narraciones que incorporan textualmente dicha tradición, en particular el Mortín Fierro: "Biografía de Tadeo Isidoro Cruz (1829-1874)" y "El Fin". ${ }^{1}$ Una lectura de este

\footnotetext{
1 Hay otros cuentos de ambiente gauchesco que por razones de síntesis no tratamos aquí. Apuntamos los más obvios en estas dos colecciones. En Ficciones (1956): "Funes el memorioso", "El Sur", y también la "Posdata de 1947" de "Tlön, Uqbar, Orbis Tertius"; en $E l$ Ale'ph (1949): "El muerto", "Historia del guerrero y la cautiva", "La otra muerte", "La intrusa".
} 
tipo jalonará no sólo el papel importante del poema de Hernández - y, por lo tanto, de toda la tradición gauchesca- en su relación con los cuentos, sino también una integración de la paradójica teoría y práctica borgiana ante la misma tradición nacional.

La mayoría de los textos críticos de Borges sobre la tradición gauchesca o bien se limitan al estudio del Martin Fierro o, al menos, incluyen reflexiones sobre el mismo. ${ }^{2}$ Emir Rodriguez Monegal, biógrafo de Borges, describe los orígenes de su interés por el poema:

El mismo Borges ha contado en qué curiosas circunstancias leyó por primera vez el Martín Fierro: tuvo que comprarlo a escondidas porque en su casa el libro estaba prohibido. Su autor, por ser federal, era enemigo de los Borges y de los Acevedo. Para Doña Leonor aquél era un libro sólo digno de maleantes o gente ignorante. Además, la imagen del gaucho que presentaba era falsa. Por eso Georgie debió leer el libro clandestinamente: para su familia era un libro políticamente pornográfico. ${ }^{3}$

Placer prohibido en la niñez, lo cual revela la profunda importancia que la lectura del poẹma adquiere para el joven Borges. La vindicación vendrá mucho después en los estudios consagrados al mismo, donde sus

2 Véanse, entre otros: "La vuelta de Martín Fierro", La Prensa, sección 2a., 24 nov. 1935, p. 2; "La poesía gauchesca" y "El escritor argentino y la tradición", en Discusión (Buenos Aires: Emecé, 1957); El "Martin Fierro" (Buenos Aires: Editorial Columba, 1953); "Prólogo" a Poesía gaucbesca, en colaboración con Adolfo Bioy Casares (México: Fondo de Cultura Económica, 1955); "El gaucho Martín Fierro", en Diamante, Series XV (London: The Hispanic and LusoBrazilian Councils, 1964); La poesia gaucbesca, a presentação (Buenos Aires: Centro do Estudos Brasileiros, 1960). En "Sobre The Purple Land" de Otras Inquisiciones (Buenos Aires: Sur, 1952) se menciona el poema de Hernández en relación con el libro de Hudson. Un primer ensayo, recogido en Inquisiciones (Buenos Aires: Proa, 1925), se limita a una discusión de la obra de Hilario Ascasubi. Otros ensayos de Borges que no se limitan a una discusión del Martin Fierro para tratar de otros aspectos de la tradición son: "El coronel Ascasubi", Sur, no. 1 (1931), págs. 68-70; "E1 Fausto criollo", Prod (2a. época, año 2), no. 11 (junio, 1925), págs. 27-30; "E1 Martín Fietro" Sur, no. 2 (1931), págs. 134 . 135; "La poesía gauchesca", Ars, no. 89, año 20 (1960), págs. 27-41; "Prólogo" a Hilario Ascasubi, Paulino Lucero, Aniceto el Gallo, Santos Vega (Buenos Aires: EUDEBA, 1960), págs. 7-12.

8 "Relecturas: El Martin Fierro en Borges y Martínez Estrada", 'Trabajo en este número de la R. I. Además de los trabajos de Borges incluidos en la nota anterior, el profesor Rodríguez Monegal menciona (pág. 7) otra conferencia de 1945, "Aspectos de la literatura gauchesca", pronunciada en Montevideo y recogida en panfleto en 1950 , que no hemos localizado. 
ideas en torno a la tradición y el poema de Hernández se repiten, con mínima modificación. Aboga repetidamente por la diferencia entre poesía gauchesca - obra de poetas cultos, urbanos, poesía de entonación y léxico propiamente gauchos y explicita en su profusión de rasgos pintorescosy poesía gaucha - la poesía "natural" de los payadores, de temas cultos y léxico inalterado. ${ }^{4} \mathrm{La}$ precisión de esta diferencia reacciona contra la tesis hegeliana de Ricardo Rojas para quien la primera no podía ser sino una derivación imperfecta de la segunda. ${ }^{5}$ En cuanto al Martín Fierro, Borges ve el poema como el punto culminante de la tradición iniciada por Bartolomé Hidalgo y continuada por Ascasubi, Del Campo y Lussich. Pero al mismo tiempo, dicha culminación conlleva una refutación del pintoresquismo que distinguía la obra de estos antecesores: "Hernández hereda la tradición de Hidalgo y Ascasubi, al mismo tiempo la contradice. Hay dos maneras de usar una tradición literaria: una es repetirla servilmente; otra —la más importante- es refutarla y renovarla." " Hernández perfecciona la entonación gaucha, naturalizando una voz poética individual y destacando el desarrollo psicológico del personaje. Por último, dicha alteración de la tradición gauchesca - la simultánea presentación del gaucho como individuo, su realidad interna, y de la pampa, su realidad externa - aproxima el Martín Fierro, según Borges, más a la novela que a la epopeya, opinión que, de nuevo, se opone a la compartida por Lugones ${ }^{7}$ y el propio Rojas ${ }^{8}$ respecto al poema. De esta manera, informa la estructura del poema un doble proyecto, cuya simultaneidad sintetiza los presupuestos rasgos de la vida gauchesca y que resulta en una ambigüedad característica de toda narración. La aparición del Martin Fierro dentro del contexto de la novelística decimonónica corrobora dicha interpretación novelística: "Novela, novela de organización instintiva o premeditada es el Martín Fierro: única definición que puede transmitir puntualmente la clase de placer que nos da y que condice sin escándalo con su fecha."' La ambigüedad de la narración significa, en último término, la propia ambigüedad moral del protagonista,

4 Véase el "Prólogo" a Poesía gauchesca, págs, viii-ix, En "El escritor argentino y la tradición", Discusión, p. 154, Borges describe la payada entre el Moreno y Martín Fierro como un intento de Hernández para hacer ver la diferencia entre los dos tipos de poesía: "Es como si el mismo Hernández hubieta querido indicar la diferencia entre su poesía gauchesca y la genuina poesía de los gauchos". Para otra descripción del mismo fenómeno, véase "El gaucho Martín Fierro", Diamante, págs. 34-35.

5 Ricardo Rojas, La litaratura argentina, Tomos VIII, IX (Buenos Aires: Juan Roldán, 1924).

p. 16.

- La poesia gauchesca (Buenos Aires: Centro do Estudos Brasileiros, 1960),

7 Leopoldo Lugones, El payador (Buenos Aires: Editorial Centurión, 1944).

8 Véase Rojas, Tomo IX, p. 815.

9 "La poesía gauchesca", Discusión, p. 36. 
cualidad que, según Borges, lo aparta definitivamente de toda naturaleza épica:

La épica requiere perfección de los caracteres; la novela vive de la imperfección y complejidad. Para unos, Martín Fierro es un hombre justo; para otros un malvado o, como dijo festivamente Macedonio Fernández, "un siciliano vengativo."10

Indudablemente, hay otras valiosas observaciones de Borges sobre el Martin Fierro. ${ }^{11}$ Algunas de ellas apuntamos más adelante. Sin embargo, de inmediato podemos deducir dos aspectos implícitos en las anteriores, el primero de los cuales lucirá evidente. Nos referimos, en primer lugar, a la precisión entre poesía gauchesca y poesía gaucha, la cual significa, en el fondo, el reconocimiento del artificio - tratamiento artístico y técnico- que informa la tradición gauchesca, artificio tradicionalmente denostado por la crítica positivista (Lugones, Rojas, Vicente Rossi) que no podía resignarse a aceptar que los poetas gauchescos no eran simples payadores. Remata Borges: "Todo esto puede resumirse así: la poesía gauchesca, que ha producido - me apresuro a repetirlo- obras admirables, es un género tan artificial como cualquier otro." 12 Dicho en otras palabras, es texto alterado basado en otro texto, voz sobre voces, literatura sobre literatura. La tradición gauchesca posee de por sí, para Borges, esa cualidad laberíntica textual que él mismo instaura en sus propias narraciones. Confundir el arte y la vida, el gaucho y su recreación literaria, equivale a no reconocer el valor artístico de la tradición, a rebajar a sus creadores. La segunda deducción, aún menos escondida, es el eslabón entre las notas críticas sobre la tradición y la incorporación de éstas en las narraciones, ya que una interpretación novelística del Martín Fierro, tal como Borges la ha enunciado, en el fondo significa una percepción de la intensidad narrativa del poema. Pero si es así, dicha percepción conlleva también su ladera opuesta, implica igualmente una conciencia de los límites narrativos de la poesía popular, los cuales, al comprobarse formalmente estrechos, frustran cualquier expectativa crítica respecto a la capacidad narrativa de la misma. Señalamos, pues, un proceso psicológico del propio autor: no es de extrañar que Borges haya superado esta implícita frustración, felizmente, al ampliar o completar el poema

10 El "Martin Fierro", p. 75. En subsiguientes citas se incluye el número de la página de esta edición en el texto.

11 Para un resumen y análisis del libto monográfico de Borges, véase el artículo de Rodriguez Monegal, antes citado.

12 "El escritor argentino y la tradición", Discusión, p. 153. Una opinión parecida se encuentra en "La poesía gauchesca", del mismo volumen, p. 12. 
en aquellas escenas que sugieren, pero que no perpetían, una posibilidad narrativa. La frustrada intuición narrativa del Borges crítico ante el Martin Fierro es satisfecha, de alguna manera, por el ejercicio del Borges narrador en dos de sus cuentos. La imprevisible consecuencia es que dichas narraciones se adhieren ya al texto de Hernández de tal manera que alteran la lectura de éste realizada por el lector moderno.

El criterio borgiano en torno a la tradición, entonces, comporta tanto la cualidad intrínsecamente meta-literaria de ésta como la naturaleza novelística de su mejor producción. La misma conciencia creadora confronta la comprensión de esta tradición con dos caras - la crítica y la creadora, una común esquizofrenia literaria- cuyas perspectivas relativamente independientes en torno a los personajes del poema, y ahora de los cuentos, jalonan una paradoja irresoluble. De esta manera, los cuentos, como demostraremos, también "refutan y renuevan" la tradición.

\section{BIOgRAFía de TAdeo IsIDORo CRUZ (1829-1874)}

Si examinamos la primera de estas narraciones, veremos hasta qué punto y de qué manera se satisface la frustración crítica que apuntamos. El cuento es de 1944 y aparece en la primera edición de El Aleph (1949). ${ }^{13}$ En ensayos anteriores o contemporáneos a la fecha de composición no aparece ningún comentario a las escenas del poema en que se basa el cuento. Sólo en El "Martín Fierro", su posterior monografía, hallamos una reacción significativa a la escena del cerco nocturno por la banda del Sargento Cruz:

La pelea se empeña en la oscuridad: Fierro, que defiende su vida, combate con una desesperación que no tienen los otros, y mata o hiere a muchos de los agresores; este coraje impresiona al sargento que manda la partida y que, increíblemente para nosotros, se pone de parte del malbechor... Cruz le cuenta su historia, que (según Juan María Torres) es la misma de Fierto; también ha matado a hombres; uno de ellos un cantor que lo provocó. (págs. 41-42.)

El comentario de Borges integra sutilmente la paradoja que advertimos y que aparecerá más evidente en el tratamiento que reciben éstas

13 Citamos por la edición a mano: El Aleph (Madrid: Alianza Editorial, 1972), p. 55. En subsiguientes citas se incluye el número de la página de esta edición en el texto. Se publicó el cuento por vez primera en Sur, no. 122 (dic. 1944), págs. 7-10. 
y otras escenas en los cuentos. Por un lado, Borges descarta toda pretensión épica de los personajes y afirma la humanidad del protagonista. Le llama "malhechor". A estas alturas del poema, después de haber cometido dos asesinatos, el calificativo no es nada inaceptable. Pero por otra parte, interesa subrayar que en la estimativa de Borges es precisamente aquella cualidad que le inyecta humanidad al protagonista, su condición de delincuente, la que revela el paralelismo de su destino con el de Cruz, la que apunta (según Juan Maria Torres y ahora según Borges) hacia su condición de doble. Líneas paralelas que mágicamente convergen en el espacio de estas escenas para el asombro del lector $y$, por consiguiente, distinción prototípica que reinstaura la inhumanidad, que subraya la naturaleza textual, de los personajes.

En el cuento propiamente, Borges aprovecha no sólo la escena del Martin Fierro, sino también la propia escritura que la informa. Por esta razón, interesa referirnos al poema de Hernández para verificar ese aprovechamiento. La escena, harto conocida, es de "El gaucho Martín Fierro". Perseguido por el asesinato de dos hombres, un moreno en una fiesta y otro gaucho en una pulpería, Martín Fierro huye de la justicia y vaga de noche por las pampas, lamentándose de su destino:

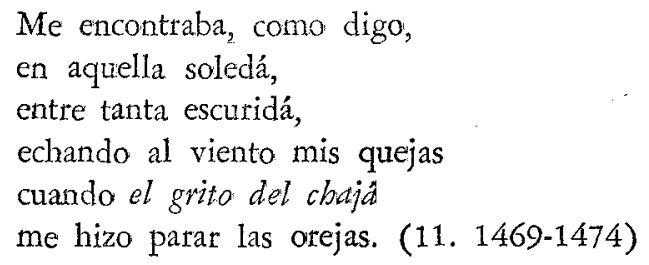

Fierro recibe la banda del sargento venciendo por si solo la mayoría del contingente. De pronto, se oye una de las voces de los atacantes, providencialmente oportuna:

Tal vez en el corazón lo tocó un santo bendito a un gaucho que pegó el grito y dijo: "Cruz no consiente que se cometa el delito de matar usi un valiente." (11. 1621-1637)

Seguidamente, el gaucho metaforiza su acción junto con la de su nuevo cómplice a base de la imagen animal: 
Y áhi no más se me aparió
dentrándole a la partida;
yo les hice otra embestida
pues entre dos era robo;
y el Cruz era como lobo
que defiende su guarida.

que defiende su guarida. (11. 1628-1632)

Más tarde, en el discurso que pronuncia Cruz se descubre, en efecto, que tanto él mismo como Fierro han asesinado en incidentes parecidos. Se confirma el paralelo cuando Fierro reconoce en su primera sextina después de hablar el sargento:

Ya veo que somos los dos

astilla del mesmo palo:

yo paso por gaucho malo

y usté anda del mismo modo. (11, 2143-2148)

En las citas del poema subrayamos aquellas frases que reaparecerán en el cuento como elementos de textura. Es evidente, sin embargo, que éste aplica un tratamiento distinto a las mismas escenas. Inicialmente, conviene aclarar que el propio título aproxima el cuento a la tradición de la biografía imaginaria, género que Borges ya había practicado anteriormente en su Historia universal de la infamia (1935). Como en aquella colección de historias tergiversadas, se practica aquí una imbricación de hechos inventados, pero precisos, para confundir al lector. ${ }^{14}$ Pero si bien el título apunta hacia esta tradición, el epígrafe que encabeza el cuento, "I'm looking for the face I had/before the world was made," tomado de un poema de Yeats, subraya el tema del doble. ${ }^{15}$

Sólo lo esencial de la circunstancia del poema, el encuentro de los dos hombres, permanece intacto en el cuento. Según el narrador: "Mi propósito no es repetir su historia. De los días y noches que la componen, sólo me interesa una noche. .." (p. 56). Seguidamente agrega:

La aventura consta en un libro insigne; es decir, en un libro cuya materia puede ser todo para todos (I Corintios 9:22), pues es capaz de casi inagotables repeticiones, versiones, perversiones. (Ibid).

14 Para un análisis de éste y otros recursos de la biografía imaginaria utilizados por Borges en este cuento véase Rodriguez Monegal, p. 11. Para una consideración del género en general, tal como ha sido practicado por Borges, véase Suzanne Jill Levine, "A Universal Tradition: The Fictional Biography", Review 73 (Spring), págs. 24-28.

$1 \bar{s}$ El Aleph, p. 55. 
Se reconoce que la circunstancia, "la aventura" proviene de otro texto, por ahora no identificado, con el cual se establecerá una suerte de diálogo para of recer otra versión de los hechos. Inventados en el cuento aparecen, entre otros hechos: la concepción de Cruz por sus padres (con que se inicia la natración), el incidente en Buenos Aires en que Cruz asesina a otro gaucho, su temporada penal en el ejército. Además, hallamos entre estas invenciones el primer cerco de un fugitivo Cruz: "Prófugo, hubo de guarecerse en un fachinal; noches después, el grito del chajá le advirtió que lo había cercado la policía." (p. 57).

Fuga, oscuridad: situación análoga a la de Martín Fierro en la escena del poema anteriormente vista. Pero más importante es notar que el verso del poema de Hernández, subrayado anteriormente, aparece ahora incrustado en este episodio imaginado de Cruz, se nos of rece otra coincidencia específica en los destinos de los dos hombres a través de la coincidencia (nada azarosa) de la escritura en los dos textos. Pero hemos de agregar que lo que hasta ahora sólo había sido una alusión a un texto no identificado, con esta incrustación se convierte en proceso intertextual: préstamo, reminiscencia de otro texto, identificado ahora por su propia escritura. ${ }^{16}$ No exageramos la importancia de este proceso. Es más, ello apura una conclusión. La reminiscencia del verso del Martin Fierro significa una lectura de la tradición gauchesca dentro del cuento, lectura que se convierte en escritura totalizante, al imbricarse, sigilosamente, en el texto: base del propio lenguaje poético según la definición de la reciente crítica estructuralista:

Le langage poétique apparaît comme un langage de textes: toute séquence se fait par tapport a une autre provenant d'ún autre corpus, de sorte que toute séquence est doublement orientée: vers l'acte de la reminiscence (évocation d'úne autre écriture) et vers l'acte de la sommation (la formation de cette écriture). ${ }^{17}$

La importancia de esta incrustación será verificada al incorporarse la misma escena del Martín Fierro en que tanto Cruz - en el cuento de

16 Para el concepto de intartexitudlidad, véase Severo Sarduy, "El Barroco y el Neo-Bartoco", en América Latina en su literatura (México: Siglo XXI, 1972), págs. 167-184. Los conceptos que describe Sarduy, aplicados al nuevo arte hispanoamericano, se derivan de discusiones del estructuralismo francés, resumidas en Phillipe Sollers, Dante et la traversée de l'écriture", Tel Quel (no, 23), págs. 21-33 y "Littérature et totalité", Tel Quel (no. 26), págs. 81-95. Un resumen más extenso lo hace Julia Kristeva, "Pour une sémiologie des paragrammes", Tel Quel (no. 27), págs. 53-75.

17 Julia Ktisteva, p. 58. Curiosamente, el concepto de la escritura como lectura de una tradición anterior había sido propuesto por el propio Borges en su "Kafka y sus precursores", ensayo de Otras Inquisiciones (Buenos Aires: Sur, 1952), págs. 126-128. 
Borges- como Fierro -en el poema de Hernández- verifican la premonición: "Gritó un chajá; Tadeo Isidoro Cruz tuvo la impresión de haber vivido ya ese momento." (p. 59). Clara estái la confirmación objetiva, la epifanía de identificación con "el otro". Pero también importa señalar que estas mismas palabras se aplican al propio proceso de lectura, el lector adquiere la impresión de haber leido ya esas palabras, "de haber vivido ya ese momento". El tiempo de la narración, así, es simultáneo al tiempo de la lectura.

Aún así, más importante que la del doble, la relación entre Cruz y Fierro es otra que se insinúa a lo largo del cuento: son simbólicamente "hijo" y. "padre" -Edipo y Layo- respectivamente. Dicha relación aparece sugerida en el propio epígrafe de Yeats, en las primeras escenas de la concepción del sargento, en el coincidente lugar de origen de Fierro y del desconocido padre de Cruz. Entendida así la relación entre los dos personajes, como dobles y como padre e hijo, se entabla una relación homológica con el diálogo que sostienen los propios textos, el seminal de Hernández y el filial de Borges, que también se reconocen en este espacio narrativo. Se alude a un momento de definitiva, aunque demorada, anagnorisis, de reconocimiento para el Sargento Cruz - pero también para el lector- con otras reconacibles incrustaciones del poema, como en la frase, "Comprendió su íntimo destino de lobo, no de perro gregario..." (p. 59). Imposible no reconocer tampoco el injerto de los versos pronunciados por el sargento: "...gritó que no iba a consentir el delito de que se matara así a un valiente." (p. 50). En el fondo, la común demora de reconocimiento para personaje y lector comporta otra relación homológica: el reconocimiento del padre equivale, para el lector, el reconocimiento de la lectura. Concluye el cuento con una explícita mención del otro gaucho - pero también del poema- "Martín Fierro", que en un final se acopla con el sargento - pero también con el cuentoen una misma dimensión textual.

Más que glosa desvinculada, más que simple derivación de una fuente literaria pretérita, el cuento intercala todo un sistema de reminiscencias textuales que permite leer en filigrana el texto del Martín Fierro, culminación de la tradición gauchesca a la cual se vincula. Advertir que era precisamente esa inherente cualidad "artificiosa", meta-literaria la que Borges asignaba a la poesía gauchesca, es otra manera de verificar ese vínculo. 
"EL FIN", O EL INTENTTO HACIA EL MÁS ALLÁ

Escrito en 1953, "El Fin" aparece en la segunda edición de Ficciones 1956)..$^{18}$ En el prólogo a "Artificios", Borges advierte sobre la naturaleza de esta narración: ". . todo lo que hay en él está implícito en un libro famoso y yo he sido el primero en desentrañarlo o, por lo menos, en declararlo."19 Las "declaraciones" de Borges sobre las últimas escenas de la payada entre Fierro y el Moreno, en que se basa el cuento, no sólo aparecen aquí, sino también en su monografía sobre el poema, ambos textos publicados en 1953. La coincidencia de fechas sugiere la posibilidad que el cuento se haya originado en las coetáneas especulaciones críticas de la monografía. Allí Borges reacciona muy curiosamente a estas escenas. Dice primero:

Aquí nos aguarda uno de los episodios más dramáticos y complejos de la obra que estudiamos. Hay todo en él una singular gravedad y está como cargado de destino. (p. 61)

Luego agrega, después de haber delatado su propio entusiasmo con las posibilidades narrativas de estas escenas:

El desafío del moreno incluye otro, cuya gravitación creciente sentimos, y prepara, prefigura otra cosa, que luego no sucede o que sucede más allá del poema. (Ibid.)

A esta últimà reacción —que indudablemente revela una suerte de ansiedad en torno a los implícitos límites narrativos del poema- añade tras citar las últimas sextinas:

Después de estas moralidades, resuelven separarse y cambiar de nombre para poder trabajar en paz. (Podemos imaginarnos una pelea más allá del poema, en la que el Moreno venga la muerte de su hermano). (p. 65.)

En las referidas escenas hallamos de nuevo tanto un imprevisible encuentro de destinos como una derivación de un texto precedente. Sin

18 Se publicó el cuento por primera vez en Ficción, no. 24.25 (11 oct., 1953), págs. 199-201.

19 Ficcione's (Buenos Aires: Emecé, 1956), p. 116. En citas subsiguientes se incluye el número de la página de esta edición en el texto. 
embargo, es evidente la diferencia básica entre esta narración y la anterior. En tanto que "Biografía" es una superimposición sobre el propio texto de Hernández, afirmada por la perspectiva del sargento Cruz, "El Fin" es una prolongación del poema hacia una dimensión inexistente, afirmada por la perspectiva de Recabarren - pulpero también inexistente, pero implícito, en el poema. Entre otras cosas, pues, "El Fin" intenta proveer una (u otra) definitiva conclusión al Matín Fierro.

Confirmemos las reacciones de Borges examinando las sextinas del poema a que se refiere. En efecto, en el poema el Moreno alude a un futuro incierto en su última intervención de la payada:

$\mathrm{Y}$ es misterio tan projundo

lo que está por suceder, que no me debo meter a echatla aquí de adivino: lo que decida el destino después lo habrán de saber. (11. 4463-4468)

Inmediatamente después de guardar silencio -e importa subrayar que éstas son las últimas palabras del Moreno- el gaucho Fierro asiente:

Yo no sé lo que vendrá tampoco soy adivino; pero firme en mi camino hasta el fin he de seguir todos tienen que cumplir con la ley de su destino. (11. 4481-4486)

El origen del título del cuento es la referida frase de Fierro, cuyo contexto, el futuro extra-textual, no es revelado al lector.

En el cuento propiamente, la narración adopta el punto de vista de Recabarren, un pulpero afásico y moribundo, paralizado por una embolia. Dicha narración avec, dada la condición incierta del personaje, produce una ambigüedad de la cual surge toda una multitud de interpretaciones de los hechos, puesto que el lector desconoce, inicialmente, si el regreso y fin de Fierro ocurre en verdad o si es parte del delirio del pulpero. La primera frase subraya la perspectiva ambigua: "Recabarren, tendido, entreabrió los ojos y vio el oblicuo cielo raso de junco". (p. 177). El nombre vasco del pulpero ya es en sí significativo, pues contiene una alusión al verbo "recabar" o "acabar", cuyo nombre, yuxtapuesto al adjetivo "tendi- 
do", premoniza la muerte, el fin, del personaje. Dentro de este contexto ambiguo aparece una primera alusión al posible diálogo con el texto de Hernández:

El ejecutor era un negro que había aparecido una noche con pretensiones de cantor y que había desafiado a otro forastero a una larga payada de contrapunto. Vencido, seguía frecuentando la pulpería, como a la espera de alguien. (p. 177).

Es preciso señalar que aunque la circunstancia referida coincide perfectamente con la que existe en el poema de Hernández, ello no constituye de por sí el proceso intertextual, no tenemos aún un diálogo. Sólo es en la segunda parte del cuento, envuelta como en sueños, que se verifican como tal tanto los gestos de los personajes como de la propia escritura. Esta precisión es necesaria para comprender el comentario del narrador que aparece seguidamente y que identifica a Recabarren como lector:

...al día siguiente, al acomodar unos tercios de yerba, se le había muerto bruscamente el lado derecho y había perdido el habla. $A$ fuerza de apiadarnos de las desdichas de los héroes de las novelas, concluimos apiadándonos con exceso de las desdichas propias; no asi con el sufrido Recabarren que aceptó la parálisis como antes había aceptado el rigor y las soledades de América. (págs. 177-178).

La confirmación de Recabarren como lector aparece en el mismo contexto ambiguo que advertimos anteriormente al negarse, en la misma frase, la excesiva piedad resultante de la lectura. No obstante, la identificación permanece: un lector que pierde el habla - como el Moreno, en el poema, había perdido el suyo. Lo curioso es que el pulpero se paraliza, a causa de una identificación literatia, en el texto en que él mismo aparece como personaje. Nuevo Don Quijote; ábrese el laberinto, produciendo un efecto de mise en abîme al aparecer ambos personajes -el identificado, Recabarren, y el identificable, el Moreno- en una misma dimensión, en un mismo texto.

Una vez que reconocemos la experiencia literaria como marco de identificación, podemos comprender los dos procesos de la narración. En primer lugat, se afirma aún más la ambigüedad al sumitse en sueños el pulpero delirante; al mismo tiempo, su experiencia como lector aclara el proceso de intertextualidad. Antes de divisarse el gaucho en el paisaje, Recabarren ya duerme: 
La llanura bajo el último sol era casi abstracta, como vista en un sueño. Un punto se agitó en el horizonte y creció hasta ser un jinete, que venía, o parecía venir, a la casa. (p. 178).

A su vez, en la siguiente conversación de Martín Fierro con el Moreno se intercala una frase del poema que confirma el acomplamiento de los dos textos y que of rece una clave para la interpretación del cuento:

Les di buenos consejos, que nunca están de más y no cuestan nada. Les dije, entre otras cosas, que el hombre no debe derramar la sangre del hombre. (p. 179).

Si ahora regresamos al poema de Hernández para realizar un rápido cotejo, confirmaremos que la frase anterior parafrasea una sextina en que aparecen otros símbolos no aludidos en la frase, pero cuyo contenido semántico se desartolla a lo largo del cuento:

El hombre no mate al hombre

ni pelée por fantasiá;

tiene en la desgracia mía

un espejo en que mirarse:

saber el hombre guardarse

es la gran sabiduría. (11. 4733-4738)

Si bien la sextina destaca el tema del doble con el símbolo del espejo - o la concepción borgiana de la unicidad de la humanidad, de todo asesinato considerado en el fondo como un suicidio-- ello también implica el reconocimiento de la irrealidad, de la fantasía como trampa. No exageraríamos ahora al notar que la noción de fantasía estaba implícita en la presentación inicial del Moreno en el poema de Hernández. Notemos cómo se destaca la coincidencia de su aparición:

Mas unza casualidat

como que nunca anda lejos,

entre tanta gente blanca

llevó también a un moreno, presumido de cantor

y que se tenía por bueno. (11. 3891-3896)

Y en la siguiente estrofa aclara su imagen inicial con un adjetivo ya para nosotros poco inocente: 
...era fantástico el negro

y para no dejar dudas

medio se compone el pecho. (11. 3904-3906)

La lectura del cuento de Borges ha así modificado y enriquecido para siempre nuestra percepción de estas escenas del poema y confirma, por otra parte, ese implícito ámbito de fantasía. Pero ante todo lo que queremos subrayar ahora es que la paráfrasis que advertimos antes, pronunciada por Fierro, significa el remiendo de una previa lectura, perpetuada ahora en sueños por Recabarren, moribundo lector. De nuevo, simultánea lectura y escritura de la tradición. Pero el proceso recibe un tratamiento aún más complejo en este cuento. En tanto que en "Biografía" la intertextualidad se llevó a cabo desde fuera, a través de un narrador impersonal, aquí se perpetúa a través de un personaje, frustrado lector, de la propia narración, cuyo proyecto es, precisamente, finalizar, "recabar" el texto anterior, el poema de Hernández, antes de morir.

$\mathrm{La}$ escritura de ese fin se realiza en el delirio. El escenario de la inevitable lucha: "Un lugar de la llanura era igual a otro y la luna resplandecía". (p. 178) Dos páginas antes, la llanura ya había aparecido como metáfora del sueño: ". . bajo el último sol, casi abstracta, como vista en un sueño". Varios hechos acontecen vertiginosamente. La demanda del Moreno al gaucho acopla las figuras del hermano muerto hace siete años y de sí mismo; se explicita el nombre del gaucho confirmando una vez más el proceso intertextual $y$, por último, se repiten a la inversa, se deshacen, dos acciones que se hallan en el texto de Hernández. Primero, la cicatrización: "Se entreveraron y el acero filoso marcó la cara del negro". (p. 180) En el poema, el Moreno es el que cicatriza a Fierro. Luego, después que Recabarren ve el definitivo "fin" - el del gaucho, el del poema y el suyo mismo - la limpieza del puñal: "Limpió el facón ensangrentado en el pasto y volvió a las casas con lentitud, sin mirar para atrás". (p. 180 $)^{20}$

Recabarren, como lector, ha acabado de escribir, en su delirio, el texto para él incompleto del poema, identificándose con el Moreno, también previamente afásico, ambos frustrados en la mudez definitiva. El Moreno es doble de su hermano, pero también lo ha sido para Recabarren, el lector. (Las palabras de Baudelaire encajan: "Hypocrite lecteur, mon

20 Nótese la reminiscencia del texto de Hernández:

Limpié el facón en los pastos

desaté mi redomón

monté despacio y salí

al tranco pa el cañandón ( $I, 1249-1252)$. 
semblable, mon frère".) También es doble del propio Martín Fierro: el asesinato ha sido en el fondo un suicidio. Qué hacemos al llegar al fin sino regresar al principio:

Cumplida su tarea de justiciero, ahora era nadie. Mejor dicho era el otro, no tenía destino sobre la tierra y había matado a un hombre. (p. 180)

Pero el Moreno como personaje soñado continúa viviendo después de eliminado Recabarren, su soñador: proceso borgiano análogo al que encontramos en otro célebre relato, "Las ruinas circulares". ${ }^{21}$ De esta manera, el ejercicio de Recabarren no es distinto al practicado por todo escritor, sus textos y personajes siguen viviendo en el texto (en el sueño) después de la muerte (o del despertar) del soñador.

\section{III}

En ambas narraciones que hemos examinado, los personajes sufren una elevación arquetipica como resultado del proceso intertextual. Para subrayar la paradoja borgiana entre el tratamiento narrativo y la humanizante actitud crítica es que insistimos en dicho proceso. El simultáneo ejercicio de escritura y lectura dispersa, inicialmente, toda cualidad del personaje como ser humano, como gaucho individual, y afirma su inherente cualidad textual. En esta afirmación yace la elevación del personaje a un grado mayor de lo que originariamente fue en el poema de Hernández, en el texto pretérito, punto culminante de una tradición. Pero si pretendemos estrechar esta paradoja entre la visión del Borges crítico y el creador caeremos víctimas de nuestro propio esquema al dejar a un lado dos importantes factores que forman parte de la valorización de los cuentos. En primer lugar, el gesto paródico, si empleamos el término "parodia" en su estricto sentido etimológico: parodos, comentario. Desde el momento en que se instaura tanto una biografía imaginaria como un proceso intertextual, una explícita escritura en filigrana, se afirma una ambigüedad paródica poco reductible, a consecuencia de su fuerza irónica, a ningún esquema como el que acabamos de trazar. En segundo lugar, se nos escapa lo más evidente. Los propios cuentos participan de esa misma modalidad narrativa que los acerca a la novela y que también identifica a sus personajes a partir de su imperfección humana. A pesar

21 Ficciones, p. 59. 
de la gran distancia formal entre la novela y el cuento, cabe aplicar a los personajes de las propias narraciones la tesis borgiana sobre la humanidad - por tanto, la imperfección- de todo personaje novelístico. La identificación entre Cruz y Fierro, en "Biografía", y la última reflexión universal del Moreno, en "El Fin", son gestos hondamente humanos, recreaciones de un inconsciente colectivo, cuyo patetismo justifica el interés por sus historias. El primero podría comprenderse -como ya hemos atisbado - a partir de una vindicación de Edipo, la salvación del padre como doble -aunque también como pretexto; el segundo como otra versión de Caín. Esas imperfecciones, esa humanidad, afirma, también paradójicamente, el heroísmo de altura arquetípica.

Al ser cotejados con el Martin Fierro, los dos cuentos revelan una nueva ordenación de los elementos de la tradición gauchesca, haciéndose de ésta un instrumento que inserta una identificación nacional y que, a su vez, rebasa los límites de ésta. Ha sido precisada la significación de este proceso en toda tradición literaria por el formalista ruso J. Tinianov en su ensayo "De l'evolution littéraire", al advertir la automatización (el carácter "trillado") que a través del tiempo adquieren ciertos elementos literarios. El la explica a base de un modelo lingüístico:

J'emprunte un exemple à la linguistique: quand l'image significative s'use, le mot qui exprime l'image devient une expression de la relation, devient un mot-outil, auxiliare. En d'autres termes, sa fonction change. Il en va de même avec l'automatisation, avec "l'usure" d'un élément littéraire quelconque: il ne disparaît pas, seule sa fonction change, devient auxiliaire. ${ }^{22}$

Su función ha cambiado: superación del "manual" de Güiraldes, Don Segundo Sombra, indagación de los estratos ecuménicos que encarna la imagen del gaucho, la experiencia gauchesca en Borges instaura una nueva manera de cumplir un "destino (literario) sudamericano". ¿Cuál es la tradición argentina?.. Creo que nuestra tradición es toda la cultura occidental". ${ }^{23}$

Borges refuta y renueva la tradición poética gauchesca afirmando la naturaleza narrativa de su mejor producción. Incorpora en sus cuentos la propia textualidad de la tradición informándola con la experiencia literaria que ésta suscita. En "Biografía", los dobles son los textos y el reconocimiento del Otro es común al personaje y al lector; en "El Fin",

22 En Théorie de la littérature. Ed. Tzqetan Todorav (Paris: Seuil, 1965), p. 125 .

28 "El escritor argentino y la tradición", p. 160. 
el personaje, también lector, satisface una frustrada lectura, la cual, a su vez, significa una nueva versión de los hechos. Por otra parte, los cuentos se convierten en metáforas de antiguos mitos, cuyo interés humano no cesa. Esa simultánea lectura y afirmación mítica destierra a los personajes a una zona perpetuamente ambigua. Condena de la entidad literaria: el texto como prisión. Es este ambiguo espacio el que la dicotomía crítica y creadora de Borges intenta captar con su paradójica percepción, la cual sólo encuentra un común denominador en el integrante gesto meta-literario que caracteriza a ambas modalidades.

ENRICO-MARIO SANTÍ

Yale University 
